\title{
Design of Web Virtual Reality for Job Interview Preparation Simulation
}

\author{
Pius Dian Widi Anggoroa1 \\ aInformatics Department, STMIK AKAKOM \\ Yogyakarta, Indonesia \\ 1piusanggoro@akakom.ac.id (Corresponding author)
}

\begin{abstract}
The implementation of Virtual Reality (VR) in education is a breakthrough in using technology to support the teaching-learning system. This study will provide more knowledge about the use of $V R$ in English classes. Students can practice answering interview questions in their own place, as often as they need. Students also can practice answering interview questions. This research is use VR technology in a web platform for job interview simulation cases. In the early stages, the evaluation to review the use of VR technology that running on low-specification smartphones (Low-Cost Device), which require a lower internet connection. The WebVR and React 360 libraries were used to develop the virtual environments and JavaScript for the language. The Web Speech API was used to convert the test into conversations by taking questions from the web service on the Moodle learning platform that was connected to PostgreSQL. The first test methods were the web application performance, then followed by Alpha Testing, a validation test by media and material experts. Than it continued in Beta Testing where a product test by 15 English class students participants. The data collection technique used a questionnaire that has to be answered by the participants. The validity and reliability tests were carried out for product usage test. The results obtained from the assessment of media experts and participant provide an assessment score of 83.10 from the experts and 77.58 from the users. The average score obtained is 80.34 which is included in the feasible category. Therefore, this learning media is ready to be used to support learning in English class.
\end{abstract}

Keywords: English Class, Job Interviews, Low Device, Software Testing, WebVR.

\section{Introduction}

The Virtual Reality (VR) system developed is known to have a game simulation product, and when used, user interaction will be like in real-life situations. Although several manufacturers later made special Head-Mounted Display (HMD) VR at a high price and still need a desktop computer (PC), it becomes popular [1]. Currently, there are also VR headsets that are made specifically with software that can run on smartphone systems that have a smaller size and do not require additional hardware. One of the contributions of mobile VR has been created by Google with Cardboard shown in Figure 1, and Daydream [2], this simple mobile VR device supports most smartphones in today's market.

The price reduction and the increased availability of the device have opened up more VR opportunities for the wider field. For example, it is included in the engineering education and training field. VR has been implemented as a promising learning tool for both formal and informal learning contexts in various educational activities [3] [4]. It is also reported that the use of immersive VR applications can provide a virtual environment to simulate challenges in teaching and thus act as a pedagogical tool for collaborative teaching/training [5]. Another common use is science learning in laboratories, in which the students perform experiments that are supposed to be dangerous or expensive, yet now can be overcome by the use of VR. For example, high school students can mix several chemicals to observe their effects safely in a virtual environment [6]. A 360-degree YouTube video channel, which is widely available and can be used for VR support in education, where learners can walk through a virtual environment to a place or to see artifacts from historical times and observe how buildings and areas have changed over the years year [7]. In Figure 2, the teachers take their students on a virtual field trip using 360-degree videos to 
immerse them in a diverse and informative environment while learning English at the same time [8]. VR video content can help students in building connections between the concepts that they learn and their influence on the world [9].

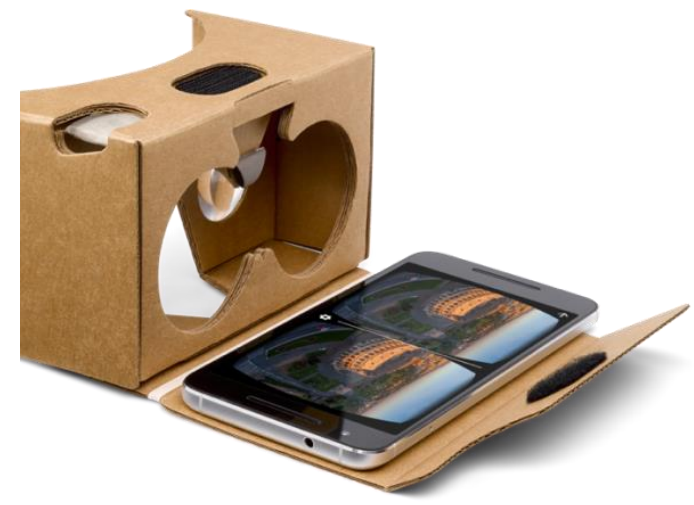

Figure 1. Google Cardboard VR version 2

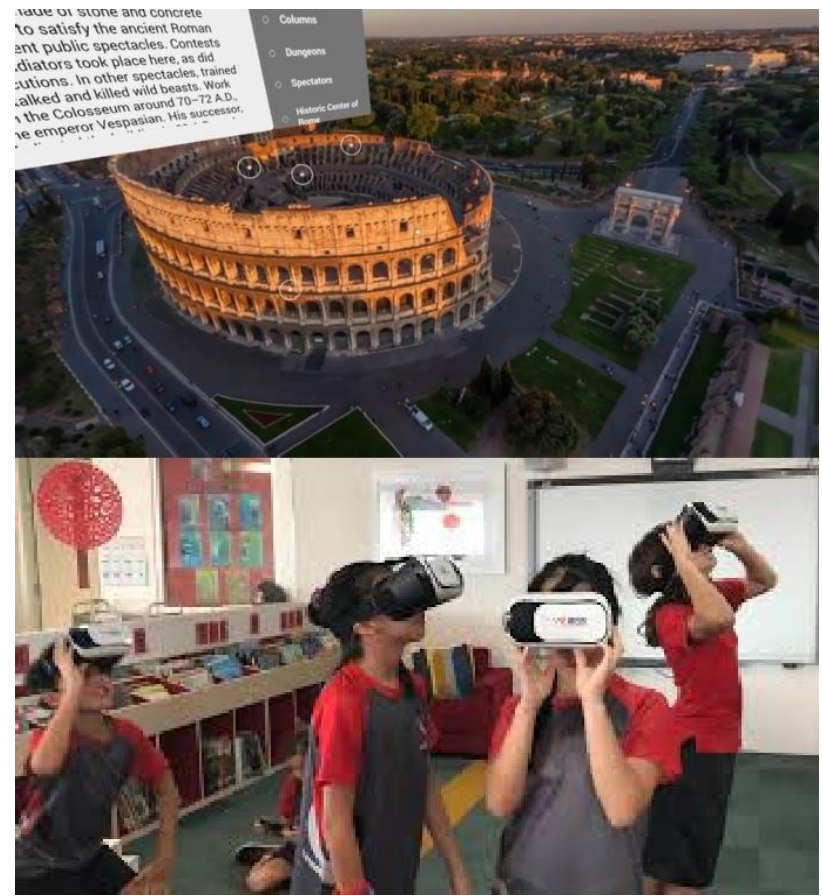

Figure 2. The Use of VR for Historical Site Exploration.

In the field of language education, VR has been used to make students having a tour in a particular place, such as an airport [10], or engaging in location-based games by walking around the city to find clues related to a story [11]. Cheng et al. [12] state that one of the English course objectives discusses the knowledge use of language vocabulary in the conversation field. One of its topics is about the preparation in the working field; job interviews. Melnik [13] identifies what prospective employees are looking for, knows what can be offered to the employers, able to prepare and promote themselves well as the most suitable people for the needs [14]. Although the use of animated robots that can simulate conversations has been studied [15], there are still some obstacles in dealing with the large file size (above 200MB) to be downloaded and installed [16]. This problem becomes the research background in achieving the goal of VR function in the education field; so, the students become more enthusiastic in learning and improving their 
speaking skills by using smartphone devices that have limited internet connections. However, more interesting experiments need to be done to say that VR will be widely used at the university level for language education.

The use of mobile VR, which is run on a set of cellular technologies, has been long recognized as a potential tool in learning [17]. Referring to the list [18] for studying and applying it in the field of language education with the challenge of using cellular service fees. First, the discussion on the portability benefits to support learning, which is not tied to one place and setting that can be arranged between formal and informal [19]. Second, in terms of mobile technology, it benefits to facilitate social interaction, which enables collaborative learning. The benefits of using VR for training to become a second language in discussions in the language field have also been improved [20], referring to [21]. Third, mobile VR offers context-sensitivity; for example, it can adapt to the user's location. It means that it can display content based on the language used in the user's location, which potentially will be able to make things easier in creating opportunities for location-based learning [22]. Furthermore, devices integrated with the mobile VR system offer connectivity and access to various resources, such as information, teachers, and other learners, which have proven in providing and supporting learning experiences [23].

How students can practice as often as they like in virtual interview scenarios, ensuring that they are ready and confident for future interviews, is the challenge for application content in VR to overcome. The content in the VR application ensures students will be better prepared, as well as the interview questions that have been asked in the job interview. They will only have one chance to impress the interviewer in real-life, so it takes a lot of practice dealing with the job interview environment. The combination of online English classes and a virtual reality platform will be able to improve their interviewing skills in a conditioned environment and learn how to communicate effectively. This study combines online classes with a VR system for a learning approach. Students are going to practice what they have learned in English classes in the VR application of job interview simulation.

Some technical problems often arise during the application development process, but eliminating the difficulties that occur will be able to reduce costs, simplify the development process, and increase optimization and usability in calculating the correct perspective [24]. As a result, the application product will be more attractive and user friendly. The possibility of achieving such simplicity is found in the idea of providing VR content in a web platform via a browser by implementing a new API called Web-VR [25].

In improving English learning in the Job Interview Training case study, web-based VR technology is implemented. This research scope is the VR system used will be integrated into a smartphone device based on a web platform, with the help of low-cost HMD equipment Cardboard VR version 2. To reduce running file size, the mobile VR application is developed by using features from the A-frame reference for WebVR and Web Speech API for its speech generation. It is hoped that the evaluation results of this study will be able to give a contribution to finding the potential pedagogical benefits of the web-based mobile VR application use in a small size file in learning English; to simulate conversations during job interviews.

This paper analysed the effectiveness of conducting job interviews in a VR environment and then examines possible deployments using a browser installed on a smartphone. The web-based Job Interview Simulation is designed to evaluate whether virtual reality job interview simulations can help improve skills and abilities to use English in conversation. In particular, the qualitative data will provide valuable insights into how participants would perceive barriers to implementing virtual reality job interview simulations.

\section{Research Methods}

The general architecture of the VR system used to develop the job interview application is shown in Figure 3. The first focus of this research is on the development of the WebVR application, which is then evaluated by the user through a questionnaire, and later, the data obtained is then analyzed. 


\subsection{Initial Observation Stage}

The user's scope in this study is the English class higher education students at Yogyakarta. To provide a research overview on the use of VR to work in language classes, initial activities are needed in the form of observations for content development based on the topic in language learning, the steps in classroom learning must be ensured that they can be implemented in the application. It details some rules that need to be created and the procedures that need to be followed, including the devices and applications used. It is also possible to introduce some technical terms that may be unfamiliar to the users.

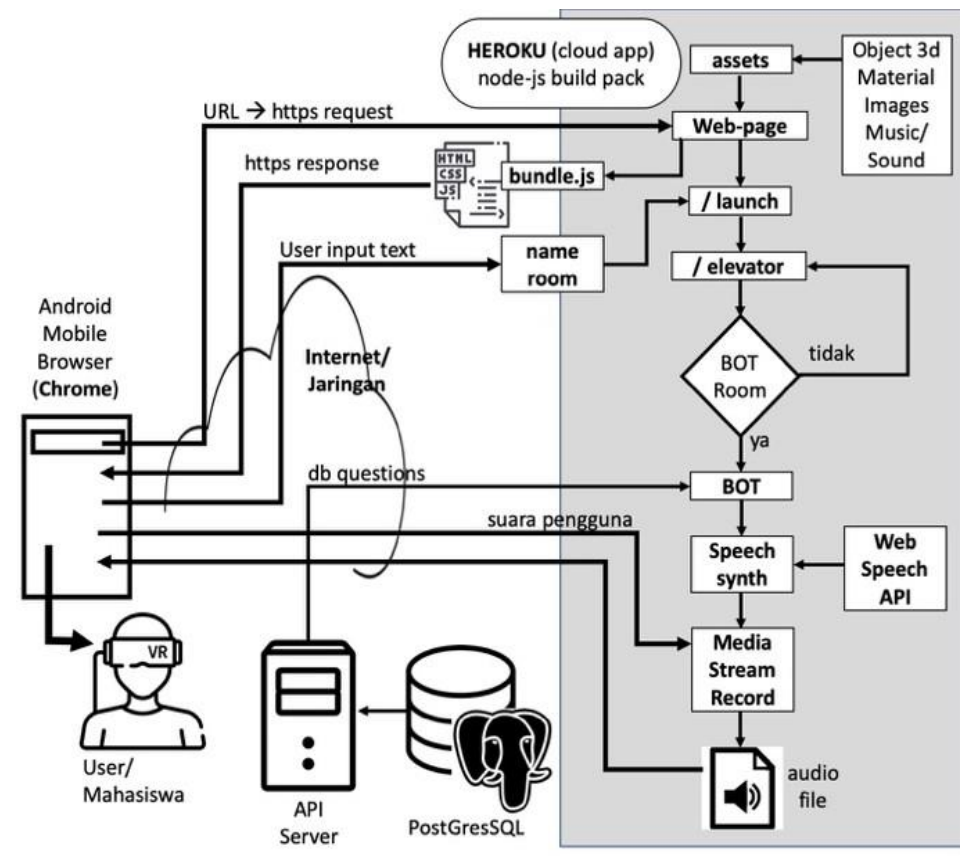

Figure 3. VR Job Interview Simulation Schematic System.

\subsection{Technology Development Stage}

There are several options for implementing a web-based VR application, but JavaScript (JS) is the main programming language to be implemented in this study. The JS reference used by Three.js and Babylon.js is made to create computer graphics and $3 \mathrm{D}$ animations. Additional frameworks, namely A-Frame and React 360 , which are specialized in browser-based VR, are also optimized to create a VR environment that is suitable for real-world job interview environments.

The virtual environment is designed for users with little experience (less than one year) in using HMD VR devices so that the virtual environment is created with a few 3D objects as possible. In the Web VR platform, these 3D objects are defined in HTML as Document Object Model (DOM) Elements. Figure 4 shows that the 3D object is a DOM when inspected in the browser.

The software which will be used is Node.js version 12.15.0. This software is chosen due to some reasons. They are: (1) free and open-source code, (2) support for JavaScript-oriented network applications that must (3) be accessible for many users at the same time (scaled). (4) The use of a V8 virtual machine as the current standard browser and (5) allows it to be developed on servers with the HTTPS protocol, without the need to set up a web server, such as Nginx or Apache. In general, Node.js is a low-level environment that allows server-side execution of JavaScript files. The most important advantage of this method is that it allows synchronous or real-time communication in its implementation on the application for the voice data acquisition feature spoken by the user. The Socket.io reference is used to make it easier to implement real-time synchronization via WebSocket, especially when running the Media Stream Recording feature added in the application to record voice conversations during VR-based job interview simulations. 
To simplify the integration of the VR interview simulation application with the English online class, the questions are taken from the Moodle web service (Restful API), a learning platform, which is already available, which uses the PostgreSQL database. Question data are obtained in the form of JSON, which is shown in Figure 5, as the response for the request to the Moodle web service in English class. Next, the JSON format is then parsed to become a text array.

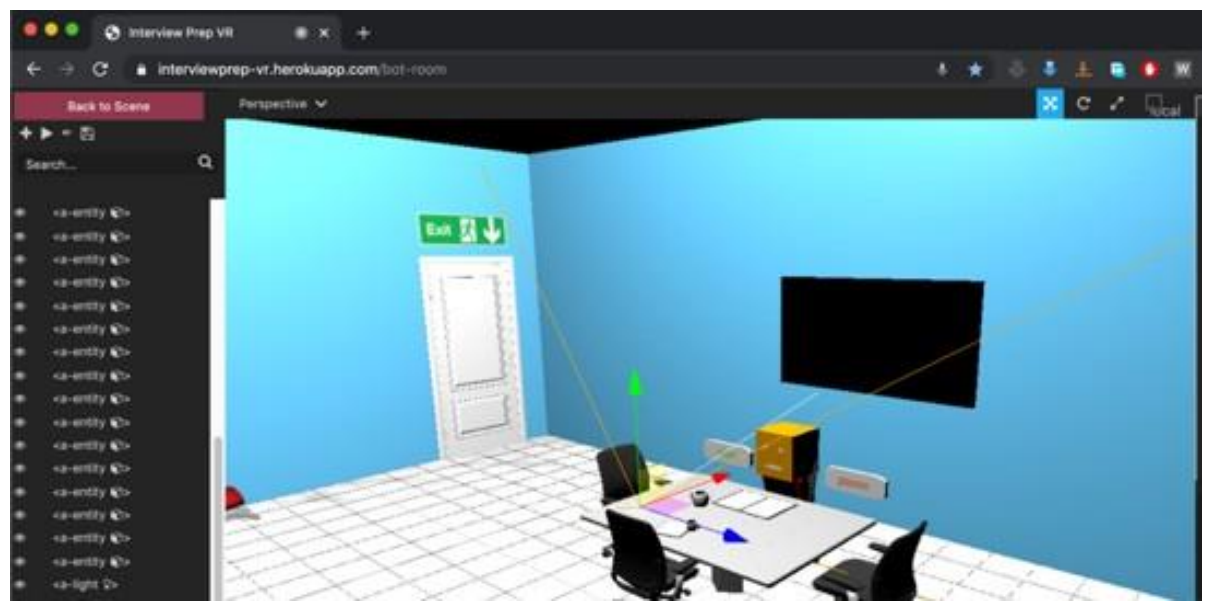

Figure 4. 3D Content Inspection during Application Development

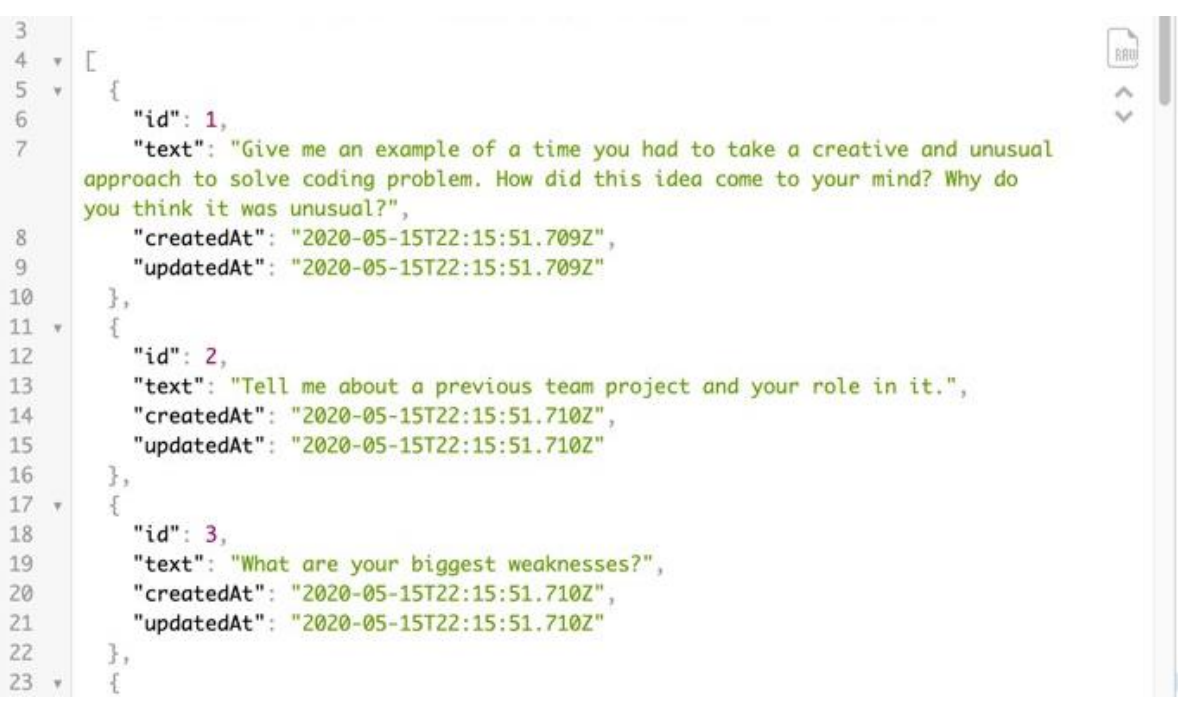

Figure 5. JSON Format for Web Service Response Results

The Web Speech API has been provided by the Mozilla Developer Network (MDN), is used to be easily implemented with JavaScript, and provides speech recognition and speech synthesis functions. Conversation detection that is captured by the microphone on the user's smartphone is carried out by the Speech Recognition function, while the speech synthesis, which changes the JSON parsed text file, is provided by the Speech-Synthesis-Utterance object. Another function is the Speech-Synthesis-Voice object, which stores the speech information used to execute the speech synthesis function.

The result of this stage is an application prototype, in which the participants can adjust the learning environment in the implementation process. Applications with VR interview simulation content can be run on a smartphone browser and with a cheap HMD Cardboard VR. The participants are given the experience in using Cardboard VR and the ability to have interact with its content, while the time limit for using it is not set to enhance the experience. The use of chatbot-like technology to receive customers' questions and answers [26] has been provided for participants to interact with the VR environment to make the results during the evaluation process are not only based on 
a one-time question model. Also, chairs are needed to enhance the participant's experience in virtual job interviews; therefore, the participants can use the movement capabilities by using HMD Cardboard VR.

\subsection{Learning Implementation}

In the research process, content that includes three-dimensional visual elements and conversational audio for learning English which is related to job interviews, will be presented. In this context, the participants can obtain information in a virtual environment by having interaction through Gaze interactions in virtual environment. The participants can answer questions from interviewing bots via smartphone devices, and the time limit is not applied to the participants while they are learning the job interview simulation process. Questionnaire filling in the form of Google Form has been provided, and the participants who have completed a job interview simulation activity are asked to fill it in.

\subsection{Data Analysis}

The testing procedure in this study is Alpha Testing; validation testing by media experts, validation testing by material experts, then testing instrument items in the form of instrument item validity testing and instrument reliability testing, and finally Beta Testing; product usage testing by the participants. Data collection techniques use a questionnaire. The questionnaire is used for data collection by giving a set of questions to be answered to the participants by using the Educational Research Methods reference [27], which refers to [28]. The questionnaire that is applied is a closed questionnaire model or the one in which the options are provided to be chosen by the participants.

The validity test is carried out on each question item. The result of $r$ count is compared with $r$ table where $\mathrm{df}=\mathrm{n}-2$ with sig $5 \%$, if $\mathrm{r}$ table $<$ rcount then each statement is declared valid. The validity test uses the Product Moment correlation technique using the following equation.

$$
r_{x y}=\frac{\left.n \sum X_{i} Y_{i}-\left(\sum X_{i}\right) \sum Y_{i}\right)}{\sqrt{\left\{n \sum X_{i}^{2}-\left(\sum X_{i}\right)^{2}\right\}\left\{n \sum Y_{i}^{2}-\left(\sum Y_{i}\right)^{2}\right\}}}
$$

$r_{x y}$ is the coefficient value of the Pearson relation, $n$ is the numbers of data pairs $X$ and $Y, \Sigma X$ and $\Sigma Y$ are the numbers of variables $X$ and variable $Y$. The reliability test is done by using the Alpha formula.

$$
r_{i}=\frac{k}{(k-1)}\left\{1-\frac{\sum \sigma_{b}^{2}}{\sigma_{t}^{2}}\right\}
$$

Where $r_{i}$ is the instrument reliability coefficient, $k$ is the number of question items, $\Sigma \sigma_{b}^{2}$ is the amount of variants items, and $\sigma_{t}^{2}$ is the total variation. After the reliability coefficient is known, then it is interpreted by using the interpretation category, as in Table 1., according to Program Evaluation Education and Training [29], which refers to [30].

Table 1. Interpretation Table of the Coefficient $r$

\begin{tabular}{cc}
\hline Coefficient $r$ & Interpretation \\
\hline $0,80<r \leq 1,00$ & High \\
$0,60<r \leq 0,80$ & Medium \\
$0,40<r \leq 0,60$ & Quite Low \\
$0,20<r \leq 0,40$ & Low \\
$0,00 \leq r \leq 1,20$ & Very Low \\
\hline
\end{tabular}

In the questionnaire used in this study, the answers to the instrument items were classified into five options. Each measured indicator is given a scale score of 1-5, namely 5 (very good / very appropriate / very feasible / very clear), 4 (good / appropriate / appropriate / clear), 3 (not good / 
not suitable / not appropriate / less clear), and 2 (not good / inappropriate / inappropriate / unclear), and 1 (very bad / very inappropriate / very inappropriate / very unclear). The next step is to assess the feasibility of a learning application to be implemented in an English course. After the data is obtained, the next step is to see the weight of each response and calculate the average score with the formula (3).

$$
\bar{x}=\frac{\sum x}{n}
$$

$\bar{x}$ is the average score, $n$ is the number of respondents, and $\Sigma x$ is the total score. Then the percentage formula for the results can be calculated by the formula (4). Where $\Sigma x$ is the total score and $x_{\max }$ is the maximum score from respondents.

$$
\text { Result }=\frac{\sum x}{x_{\max }} \times 100 \%
$$

Eligibility categories based on criteria) are shown in Table 2 .

Table 2. Application Eligibility Category Table

\begin{tabular}{cc}
\hline Result (\%) & Category \\
\hline Score $\leq 20 \%$ & Very Inappropriate \\
$20 \%<$ Score $\leq 40 \%$ & Inappropriate \\
$40 \%<$ Score $\leq 60 \%$ & Quite \\
$60 \%<$ Score $\leq 80 \%$ & Appropriate \\
$80 \%<$ Score $\leq 100 \%$ & Very Appropriate \\
\hline
\end{tabular}

\section{Result and Discussion}

Before filling out the assessment instruments provided, each participant first tested the web-based InterviewPrep VR application. Figure 6 is a screenshot of an application in the VR mobile web platform that has been successfully developed and run on the Chrome browser.

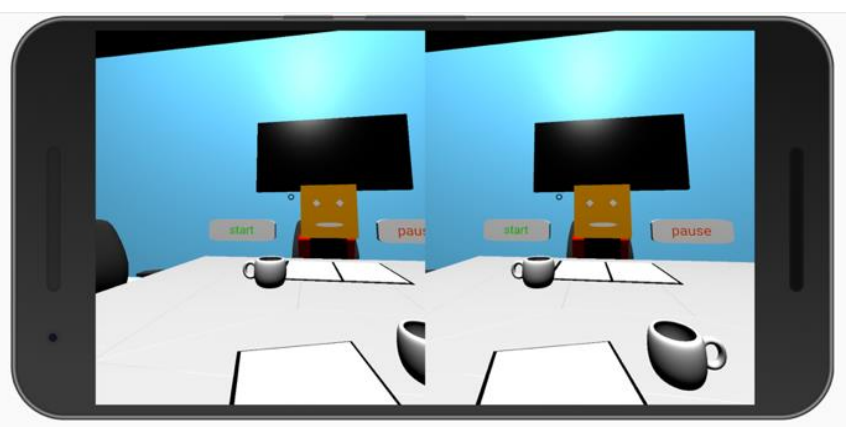

Figure 6. Application is Running on Mobile Devices 


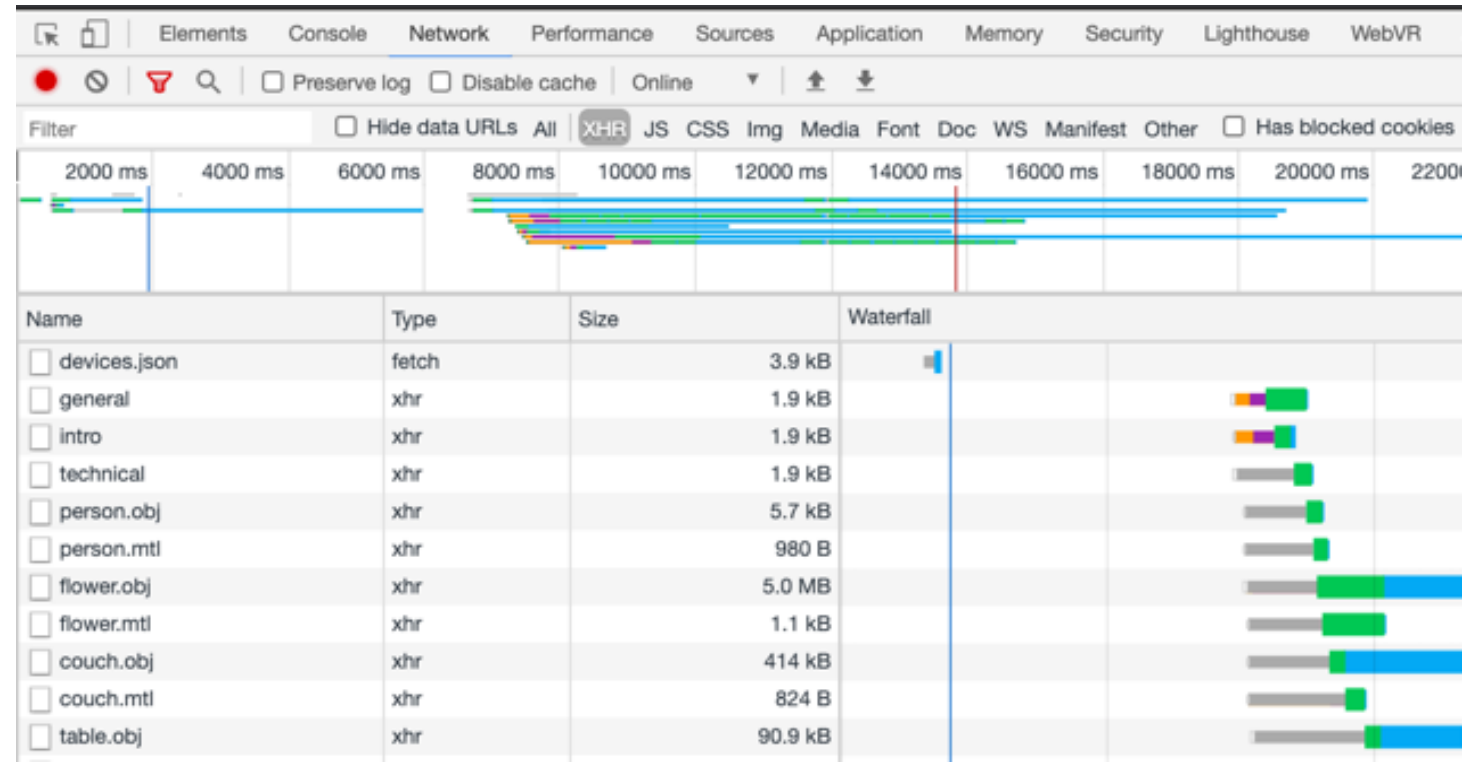

Figure 7. Performance Analysis Results.

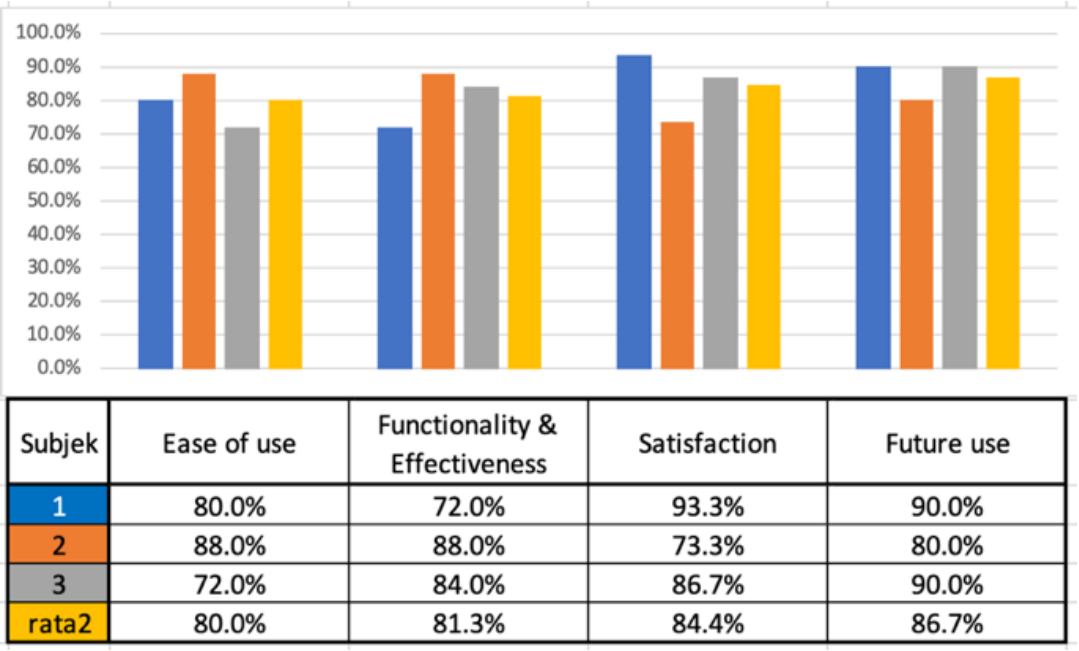

Figure 8. The Assessment Results of The Media and Material Experts

The results of the validation test by media and material experts are in the form of their responses and assessments, then the results of the data obtained are analyzed, and the application product is revised according to suggestions. Figure 8 shows that the feasibility percentage in terms of the Easy of Use aspect of three experts, which obtains an average value of $80.00 \%$. Based on the aspects of Functionality and Effectiveness, the average data obtained is $81.30 \%$. Satisfaction aspects obtained average data of $84.40 \%$. Future Use aspects get average data of $86.70 \%$. The total percentage of all aspects obtained from the three experts is $83.10 \%$, so the Alpha series test shows the results of implementing VR web for job interview learning media are categorized as very feasible to be used.

Table 3. Instrument Validity Calculation Results

\begin{tabular}{cccccccccccccc}
\hline Questionnaire & $\mathbf{1}$ & $\mathbf{2}$ & $\mathbf{3}$ & $\mathbf{4}$ & $\mathbf{5}$ & $\mathbf{6}$ & $\mathbf{7}$ & $\mathbf{8}$ & $\mathbf{9}$ & $\mathbf{1 0}$ & $\boldsymbol{r}_{\boldsymbol{x y}}$ & $\boldsymbol{t}_{\text {count }}$ & Test \\
\hline 1 & 3 & 3 & 4 & 4 & 4 & 3 & 4 & 5 & 5 & 3 & 0.462 & 2.208 & valid \\
2 & 3 & 4 & 5 & 5 & 4 & 3 & 4 & 3 & 3 & 4 & 0.764 & 5.025 & valid \\
3 & 4 & 3 & 4 & 4 & 3 & 4 & 3 & 4 & 5 & 4 & 0.250 & 1.796 & valid \\
4 & 3 & 3 & 5 & 3 & 5 & 4 & 5 & 3 & 3 & 3 & 0.412 & 1.920 & valid
\end{tabular}




\begin{tabular}{cccccccccccccc}
\hline Questionnaire & $\mathbf{1}$ & $\mathbf{2}$ & $\mathbf{3}$ & $\mathbf{4}$ & $\mathbf{5}$ & $\mathbf{6}$ & $\mathbf{7}$ & $\mathbf{8}$ & $\mathbf{9}$ & $\mathbf{1 0}$ & $\boldsymbol{r}_{\boldsymbol{x y}}$ & $\boldsymbol{t}_{\text {count }}$ & Test \\
\hline 5 & 3 & 4 & 5 & 5 & 5 & 4 & 5 & 3 & 4 & 3 & 0.197 & 1.853 & valid \\
6 & 5 & 2 & 4 & 4 & 3 & 4 & 3 & 4 & 3 & 4 & 0.397 & 1.835 & valid \\
7 & 4 & 4 & 3 & 5 & 4 & 4 & 4 & 4 & 3 & 4 & 0.398 & 1.840 & valid \\
8 & 5 & 3 & 3 & 5 & 5 & 3 & 5 & 4 & 5 & 4 & 0.398 & 1.841 & valid \\
9 & 5 & 3 & 4 & 3 & 5 & 3 & 3 & 3 & 3 & 4 & 0.521 & 2.591 & valid \\
10 & 3 & 1 & 5 & 4 & 4 & 2 & 5 & 3 & 4 & 5 & 0.479 & 2.312 & valid \\
11 & 3 & 4 & 5 & 5 & 5 & 4 & 3 & 3 & 3 & 4 & 0.452 & 2.151 & valid \\
12 & 3 & 3 & 5 & 5 & 5 & 5 & 4 & 4 & 3 & 3 & 0.470 & 2.257 & valid \\
13 & 3 & 3 & 5 & 5 & 5 & 3 & 5 & 3 & 3 & 4 & 0.598 & 3.169 & valid \\
14 & 4 & 4 & 4 & 3 & 5 & 3 & 4 & 3 & 3 & 4 & 0.452 & 2.151 & valid \\
15 & 3 & 4 & 2 & 4 & 4 & 4 & 5 & 3 & 4 & 5 & 0.435 & 2.051 & valid \\
\hline Total & 54 & 48 & 63 & 64 & 66 & 53 & 62 & 52 & 54 & 58 & 0.445 & 1.734 & \\
\hline \multicolumn{7}{c}{}
\end{tabular}

The validity test is carried out by testing the Interview Prep VR application on 15 English class students. Then the data obtained are analyzed using the Product Moment correlation technique with the help of Microsoft Excel application to determine instrument validity before it was used for testing. Validity results are presented in Table 3.

In this study, reliability testing with internal consistency is carried out by testing the instrument's only once, then the data obtained are analyzed. The analysis results can be used to predict the instrument's reliability. Table 4 is the Alpha test results used for reliability testing. Based on Table 4 , the interpretation of the r-value from the calculation results is 0.811 . Then the instrument reliability is included in the high category so that the test instrument used can be trusted when it is used for testing usage.

The interpretation of the validity and reliability coefficients are both relatives. The estimation of the validity of $R-x y$, ranging from 0.445 , can be considered satisfactory. While the reliability results are stated by the $r$-value reliability coefficient is 0.811 , where the higher the reliability coefficient is closer to 1.00. Reliability can be considered satisfactory if the coefficient is at least 0.900 , but in this study, it is still considered meaningful because it is used with performance tests in the devices used.

Table 4. Instrument Reliability Calculation Results

\begin{tabular}{|c|c|c|c|c|c|c|c|c|c|c|c|}
\hline Questionnaire & 1 & 2 & 3 & 4 & 5 & 6 & 7 & 8 & 9 & 10 & Variance \\
\hline 1 & 3 & 3 & 4 & 4 & 4 & 3 & 4 & 5 & 5 & 3 & 0.766 \\
\hline 2 & 3 & 4 & 5 & 5 & 4 & 3 & 4 & 3 & 3 & 4 & 0.747 \\
\hline 3 & 4 & 3 & 4 & 4 & 3 & 4 & 3 & 4 & 5 & 4 & 0.516 \\
\hline 4 & 3 & 3 & 5 & 3 & 5 & 4 & 5 & 3 & 3 & 3 & 0.829 \\
\hline 5 & 3 & 4 & 5 & 5 & 5 & 4 & 5 & 3 & 4 & 3 & 0.787 \\
\hline 6 & 5 & 2 & 4 & 4 & 3 & 4 & 3 & 4 & 3 & 4 & 0.832 \\
\hline 7 & 4 & 4 & 3 & 5 & 4 & 4 & 4 & 4 & 3 & 4 & 0.682 \\
\hline 8 & 5 & 3 & 3 & 5 & 5 & 3 & 5 & 4 & 5 & 4 & 1.103 \\
\hline 9 & 5 & 3 & 4 & 3 & 5 & 3 & 3 & 3 & 3 & 4 & 0.766 \\
\hline 10 & 3 & 1 & 5 & 4 & 4 & 2 & 5 & 3 & 4 & 5 & 1.253 \\
\hline 11 & 3 & 4 & 5 & 5 & 5 & 4 & 3 & 3 & 3 & 4 & 0.853 \\
\hline 12 & 3 & 3 & 5 & 5 & 5 & 5 & 4 & 4 & 3 & 3 & 0.800 \\
\hline 13 & 3 & 3 & 5 & 5 & 5 & 3 & 5 & 3 & 3 & 4 & 0.997 \\
\hline 14 & 4 & 4 & 4 & 3 & 5 & 3 & 4 & 3 & 3 & 4 & 0.450 \\
\hline 15 & 3 & 4 & 2 & 4 & 4 & 4 & 5 & 3 & & 5 & 0.976 \\
\hline \multirow[t]{2}{*}{ Total } & 54 & 48 & 63 & 64 & 66 & 53 & 62 & 52 & 54 & 58 & \\
\hline & & & & & & & & & $\begin{array}{l}\text { anc } \\
\text { rian } \\
\text {-val }\end{array}$ & & $\begin{array}{r}12.355 \\
36.766 \\
0.811\end{array}$ \\
\hline
\end{tabular}

In this research, the usage test is carried out by 15 participants who were randomly selected from 30 English class students. Students participating in the English class became the focal point of data collection and, thus, the main source of data. Student surveys provide a cheaper alternative to obtain data that is timely and more relevant in understanding the problems studied in this 
research. The application of the respondent selection procedure is expected to increase the validity and reliability of the survey.

The instrument used includes four aspects. They are: Easy of Use, Functionality and Effectiveness, Satisfaction, and Future Use. Instruments that are valid and reliable are used to test usage, with the test results shown in Figure 9.

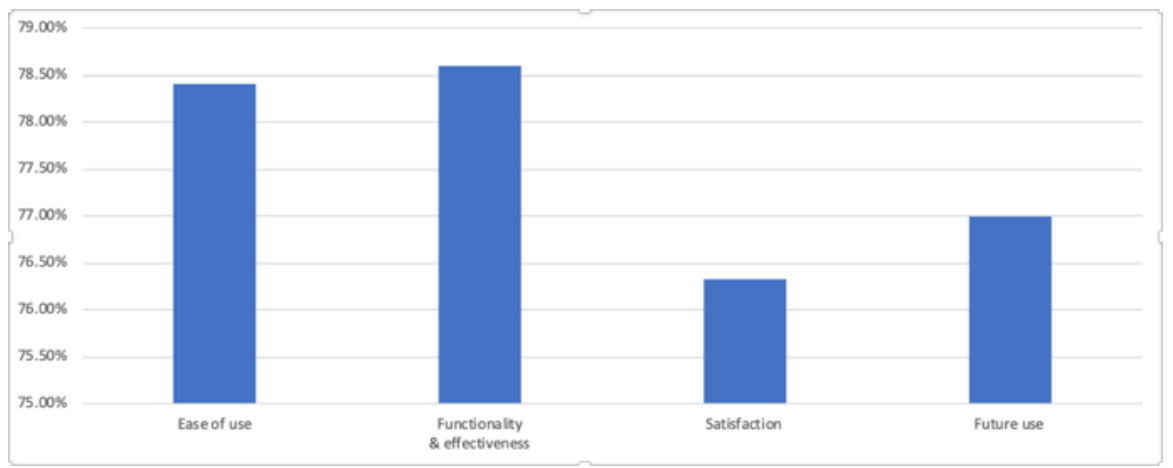

Figure 9. The Assessment Results of Test Participants.

Figure 9 shows that the eligibility percentage in terms of Easy of Use has an average value of $78.4 \%$. Based on the aspects of Functionality and Effectiveness, the average score is $78.6 \%$. In comparison, the Satisfaction aspect obtained an average value of $76.33 \%$. The Future Use aspect obtains an average value of $77.00 \%$. The total percentage of all aspects which are obtained from the participant's assessment as the respondents are $77.58 \%$. So, it can be concluded that the use of VR for learning English in a job interview simulation case study is categorized as feasible to be used.

Learning media using a 3D model with a VR web platform has proven feasible in conveying information that visualizes and simulates English conversation material that has been difficult to do conventionally. It has a positive potential since the overall resource size of the application is much smaller than the PC-based and mobile native VR platforms. Besides, it can also be accessed from many platforms as long as the VR browser has been integrated/installed. Based on the operational considerations, for the successful application of this study when viewed from constructivism learning theory [31], students must be actively involved and become the center of learning activities. Students must be able to apply and practice their skills independently, at a particular time and location that they can set by themselves. Therefore, the goal of learning conversational skills in English for job interviews can be better achieved.

\section{Conclusion}

Based on the research results and discussion, it is concluded that the use of web platform-based Virtual Reality technology for learning English in the job interview case study preparation simulations can be categorized as feasible to be used as a learning medium. According to the experts and test participant's assessment, each of them gave an assessment score of $83.10 \%$ of the media and material experts and $77.58 \%$ of the participants. This score is in the proper category, so the VR Interview application is ready to be used to support learning in English courses.

\section{References}

[1] K. Drummond, T. Houston and T. Irvine, The Rise And Fall And Rise Of Virtual Reality, New York: Vox Media, 2016.

[2] J. Tham, A. Duin, L. Gee, N. Ernst, B. Abdelqader and M. McGrath, "Understanding Virtual Reality: Presence, Embodiment, And Professional Practice.," IEEE Transactions on Professional Communication, vol. 61, no. 2, pp. 178-195, 2018. 
[3] M. Jou and J. Wang, "Investigation Of Effects Of Virtual Reality Environments On Learning Performance Of Technical Skills.," Computers in Human Behavior, vol. 29, no. 2, pp. 433443, 2016.

[4] K. Hew and W. Cheung, "Use Of Three-Dimensional (3-D) Immersive Virtual Worlds In K12 And Higher Education Settings: A Review Of The Research," British journal of educational technology, vol. 41, no. 1, pp. 33-55, 2018.

[5] M. Quintana and S. Fernandez, "A Pedagogical Model To Develop Teaching Skills. The Collaborative Learning Experience In The Immersive Virtual World TYMMI," Computers in Human Behavior, vol. 51, pp. 594-603, 2015.

[6] J. Ferrell, J. Campbell, D. McCarthy, K. McKay, M. Hensinger, R. Srinivasan and S. Schneebeli, "Chemical Exploration With Virtual Reality In Organic Teaching Laboratories," Journal of Chemical Education, vol. 96, no. 9, pp. 1961-1966, 2019.

[7] R. Khoerniawan, I. Putrama and K. Agustini, "Game Edukasi Penjelajah Berbasis Virtual Reality," KARMAPATI (Kumpulan Artikel Mahasiswa Pendidikan Teknik Informatika), pp. 20-29, 2018.

[8] I. Craddock, "Immersive Virtual Reality, Google Expeditions, And English Language Learning," Library Technology Reports, vol. 54, no. 4, pp. 7-9, 2018.

[9] L. Meyer, "Students Explore The Earth And Beyond With Virtual Field Trips," THE Journal, vol. 43, no. 3, pp. 22-25, 2016.

[10] H. Reinders, O. Lakarnchua and M. Pegrum, "A Trade-Off In Learning: Mobile Augmented Reality For Language Learning," Contemporary Task-Based Language Teaching in Asia, vol. 15, pp. 244-256, 2015.

[11] C. Holden and J. Sykes, "Leveraging Mobile Games For Place-Based Language Learning," International Journal of Game-Based Learning, vol. 1, no. 2, pp. 1-18, 2018.

[12] A. Cheng, L. Yang and E. Andersen, "Teaching Language And Culture With A Virtual Reality Game," in CHI Conference on Human Factors in Computing Systems, 2017, Colorado.

[13] J. Melnik, "Get That Job! the Quick and Complete Guide to a Winning Interview," Career Planning and Adult Development Journal, vol. 34, no. 3, p. 28, 2018.

[14] M. Smith and M. Bell, "Response: Importance of Virtual Reality Job Interview Training in Today's World," The Journal of Nervous and Mental Disease, vol. 204, no. 10, p. 800, 2016.

[15] M. Schmid, E. Kleinlogel and M. Bachmann, "The Future Of Interpersonal Skills Development: Immersive Virtual Reality Training With Virtual Humans," Human Resource Development Quarterly, vol. 29, no. 2, pp. 125-141, 2018.

[16] M. Jailani and L. Nurbatra, "Virtual Reality System For Job Interview Application: A Development Research," Celtic: A Journal of Culture, English Language Teaching, Literature and Linguistics, vol. 6, no. 1, pp. 31-50, 2019.

[17] H. Reinders and M. Pegrum, "Supporting Language Learning On The Move. An Evaluative Framework For Mobile Language Learning Resources," Second Language Acquisition Research and Materials Development for Language Learning(Eds.), pp. 116-141, 2015.

[18] E. Klopfer, K. Squire and H. Jenkins, "Environmental Detectives: PDAs As A Window Into A Virtual Simulated World," IEEE Wireless and Mobile Technologies in Education, pp. 95-98, 2012.

[19] S. Li, Y. Chen, D. Whittinghill and M. Vorvoreanu, "A Pilot Study Exploring Augmented Reality To Increase Motivation Of Chinese College Students Learning English," Computers in Education Journal, vol. 6, no. 1, pp. 23-33, 2015.

[20] C. Chapelle, Computer Applications in Second Language Acquisition. Foundations for Teaching, Testing, and Research, Cambridge: Cambridge University Press, 2017.

[21] M. Warschauer, "Computer-Mediated Collaborative Learning: Theory And Practice," The Modern Language Journal, vol. 81, no. 4, pp. 470-481, 2017.

[22] H. Wang, G. Liu and G. Hwang, "Integrating Socio-Cultural Contexts And Location-Based Systems For Ubiquitous Language Learning In Museums," British Journal of Educational Technology, vol. 48, no. 2, pp. 653-671, 2015. 
[23] K. Schwienhorst, Learner Autonomy and CALL Environments, New York: Routledge, 2016.

[24] M. Letić, K. Nenadić and L. Nikolić, "Real-Time Map Projection In Virtual Reality Using WebVR," International Convention on Information and Communication Technology, Electronics, and Microelectronics (MIPRO), pp. 1439-1443, 2018.

[25] C. Dibbern, D. Krupke and F. Steinicke, "Can Webvr Further The Adoption of Virtual Reality?," Mensch und Computer, pp. 377-384, 2018.

[26] R. Chua, "FAQ Chatbot Web Framework For Response Comparisons And Performance Analysis," Nanyang Technological University, Singapore, 2020.

[27] Sugiyono, Metode Penelitian dan Kuantitatif, Kualitatif, dan R\&D, Bandung: Alfabeta, 2016.

[28] Sugiyono, Metode Penelitian Pendidikan (Pendekatan Kuantitatif, Kualitatif, dan R\&D), Bandung: Alfabeta, 2019.

[29] T. Aryanti, S. Supriyono and I. Ishaq, "Evaluasi Program Pendidikan dan Pelatihan," Jurnal Pendidikan Nonformal, vol. 10, no. 1, pp. 1-13, 2018.

[30] Arikunto, Suharsimi and A. Safruddin, Evaluasi Program Pendidikan, Jakarta: Bumi Aksara, 2019.

[31] Ningsih, "Aplikasi Teori Belajar Konstruktivisme dalam Pembelajaran Bahasa Asing," FOUNDASIA, vol. 9, no. 1, pp. 43-54, 2018. 